\title{
A STUDY OF PROFESSIONAL MOBILITY IN A LARGE CORPORATION THROUGH COGNITIVE MAPPING
}

\author{
Luiz Flávio Autran Monteiro Gomes* \\ $\mathrm{Ibmec} / \mathrm{RJ}$ \\ Rio de Janeiro - RJ, Brazil \\ autran@ibmecri.br
}

Luís Alberto Duncan Rangel

EEIMVR / Universidade Federal Fluminense (UFF)

Volta Redonda - RJ, Brazil

duncan@metal.eeimvr.uff.br

Rogério Lúcio Jerônimo

Petrobras - Petróleo Brasileiro S.A.

Rio de Janeiro - RJ, Brazil

rjeronimo@petrobras.com.br

* Corresponding author / autor para quem as correspondências devem ser encaminhadas

Recebido em 06/2009; aceito em 04/2010 após 1 revisão

Received June 2009; accepted April 2010 after one revision

\begin{abstract}
Decisions which are made by executives in large corporations regarding professional mobility cause changes to both their personal and professional lives. This research was carried out with the aim of creating the structuring of a professional mobility problem through the use of a decision support tool, the cognitive mapping. Through the use of this tool, a decision making structure for professional mobility was developed, taking into consideration some important aspects of this process. The cognitive mapping proposed here was a problem structuring tool which leads decision makers to a greater understanding of the problem, giving them support towards good decision making in professional mobility. Through the research carried out it was possible to identify the principal factors which lead these professionals to a professional mobility decision which is as coherent and consistent as possible with the subjective aspects of their professional reality.
\end{abstract}

Keywords: cognitive mapping; decision support; professional mobility.

\section{Resumo}

As decisões com relação à mobilidade profissional tomadas por executivos em grandes corporações causam mudanças em suas vidas pessoais e profissionais. A presente pesquisa foi desenvolvida com o objetivo de estruturar o problema da mobilidade profissional através de uma ferramenta de suporte à decisão: o mapa cognitivo. Esta ferramenta promove uma maior compreensão do problema pelos tomadores de decisão. Através da pesquisa desenvolvida foi possível identificar os principais fatores que levaram os profissionais a tomar a decisão de mobilidade de forma o mais coerente e consistente com os aspectos subjetivos de sua realidade profissional.

Palavras-chave: mapas cognitivos; apoio à decisão; mobilidade profissional. 


\section{Introduction}

Decision making by an individual or by a group of people considering aspects of professional mobility within a large corporation causes changes at a personal and professional level. Achieving personal and professional objectives is not the easiest of tasks. The objectives to be reached associated with other fundamental elements in the lives of individuals, such as family, career and quality of life, are difficult tasks.

Normally these objectives are conflicting and the choices, with considerations of trade-offs, form part of those decisions which must be taken every day. Chaplin (1985) comments on the adaptive behaviour of individuals in interacting more satisfactorily with their environment, seeking a harmonious relationship between the physical and social environment in order to satisfy their needs.

Decision making support systems help people make intelligent decisions on various aspects of operations as they supply important information, in an appropriate format, so that they may identify, simulate, calculate, evaluate, synthesize and compare before making the decision (Clemen \& Reilly, 2001). For Keeney \& Raiffa (1999), what makes the situation problematic for the decision makers is that they are being pressured to reach a decision which is not yet clear to them.

In approaching a decision problem various phases are carried out. For Bana e Costa et al. (2002), the decision support process involves three phases: structuring; evaluation; and recommendation. For Keeney (1992), decision makers must express their values through the objectives to be reached, characterised by three aspects: a decision context, an object and a direction of preference.

One of the tools which can be used to help people make decisions in this context is the creation of a cognitive map of the problem. The cognitive map assists in the explication of the strategic objectives and in the identification of the fundamental values of the decision maker (Montibeller Neto, 1996).

Cognitive mapping is a structuring tool for decision making problems. This tool has been applied in diverse knowledge areas, more specifically in administration. The main advantage it presents for the decision maker is the possibility to increase the level of knowledge of the subject, during the construction of the map, leading him/her to reflect on more coherent and intelligent decision making, according to the problem to be structured.

It is common for people to wish to leave the company where they work (change companies) at some moment in their lives or for them to leave the place where they were born to move to another in the search for new opportunities and new challenges. This study was conducted with employees of a corporation that has the characteristic of employment "stability". Thus that corporation does not have a culture of firing employees and presents a very low turnover of employees. Mobility in this large corporation occurs more within the organization itself and it was with this vision that the research was carried out. In this way, the mobility of employees within the company itself was analysed through the construction of a cognitive map. Information was obtained from a group of employees about a problem common to all of them: decision making concerning professional mobility. Data were collected through applying questionnaires. These data allowed building cognitive maps that explained the decision making processes associated to that professional mobility. 
The purpose of the research was to identify, through the use of the cognitive mapping tool, the main factors which affect a group of employees in a large corporation when making a decision about professional mobility.

\section{Cognitive mapping}

\subsection{Definitions}

A cognitive map is a graphic representation, where each node is a concept and the links indicate causality. It is a representation of causes and effects (or means-ends) concerning a determined situation. They are constructed from dialogues with an agent involved in a determined process (Rosenhead \& Mingers, 2008).

For Eden (1988) a cognitive map is a way to represent the problem of the decision agent, as well as dealing with groups of decision makers, each with their own problem. For Gomes, Gomes \& Almeida (2009), cognitive mapping is the technique which permits the representation of ideas, feelings, values, attitudes and their inter-relations, in such a way as to make a study and a later analysis possible, using, for this purpose, a graphic representation. The process is discursive, as it represents the discourse of the decision maker himself/herself, normally realised by means of a dialogue. The map is reflective as it encourages reflection and thought. People are given time and are encouraged to think about what they will say. Their ideas and comments must be reflected in the existing concepts. The cognitive map is also a resource as the decision maker has the recourse of observing the map, interlacing comments and reviewing his/her own ideas. The fact of having said something at a given moment may after some steps be seen as no longer valid. Therefore the decision maker goes back to the previous stage and reviews his/her first comments. This characteristic enriches the decision maker's vision of the problem and improves his/her decision making.

Cognitive maps can supply skill in writing, stimulating or prognosticating thought. In this way, the requirements which can be made for a cognitive map as an artefact are that it can represent more meaningful subjective data than other models, providing assistance for researchers interested in subjective knowledge and, in this way, act as an instrument which assists in the decision making and the negotiation of problems (Eden, 1988). For cognitive maps to be understood and for them to support a decision making process they must present the following characteristics, according to Bastos (2002): they must be representations of the reality; they must be updated from the experiences of the subject, and they must be flexible and used to perceive the relations between varied behaviour and similar results.

Cognitive maps can be classified in many ways. In terms of types, the maps can be classified in: maps of points and maps of context. In terms of use they can be employed as: products (remaining stable over time) or as tools, of a dynamic character which may be subject to modification (or abandonment) by the decision makers (Fiol \& Huff, 1992), in the face of complex questions. In terms of components, cognitive maps can be: of identity, of categorisation and causes or of argumentation. In terms of type of intervention, cognitive maps can be: organizational or individual. In terms of analysis, cognitive maps can have: hierarchical analysis or cybernetic analysis.

The labels that are displayed in cognitive maps emerge from the nature of the decision problem under consideration. Labels are thus established by the decision makers as results from questions which are considered important and are raised by them about that problem.

Pesquisa Operacional, v.30, n.2, p.331-344, Maio a Agosto de 2010 
The label definition phase is fundamental for the construction of a cognitive map. For instance, the use of a label that does not really reflect the decision problem under analysis can create difficulties to the building of that map. Besides, it can also lead to its abandonment during the process of constructing the cognitive map.

\subsection{Elements of Cognitive Mapping}

In the construction of a cognitive map a tool is used to extract the Primary Evaluation Elements (PEEs) from the decision makers, such as brainstorming, for example. These elements are made up of objectives, goals, the values of the decision makers, actions, alternatives and options. The procedure is to encourage the decision makers to give the first insights which come to mind about the subject, at the beginning of the PEEs. The greatest possible number of these manifestations should be collected. At this point any critique that could block the generation of new insights should be avoided. This stage is fundamental for the construction of the cognitive map (Jardim, 2008). A reduced number of PEEs may prejudice the result, which will compromise the structure of the map. For this reason, the facilitator must be aware of the need to maintain focus.

After the identification of each PEEs, a concept must be constructed. The text of each concept must have a perspective towards an action in the imperative form and must be expressed by an abbreviated text (Jardim, 2008). The description of each concept begins with the definition of the pole present and will only have meaning in the light of its psychological opposite (contrasting pole). The contrasting pole, the psychological opposite, can also be understood as the alternative that the decision maker considers acceptable, when there is no possibility of obtaining, immediately, the action shown in the first pole. There is no fixed rule for the definition or codification of the first pole. The opposite pole is important to the extent that the concept only makes sense when there is a contrast between the poles.

According to Jardim (2008), a system which can be recommended is for the facilitator to adopt, as the first pole, the first description pronounced by the decision maker, the result of the first perception which came to mind, whether positive or negative.

In the conception of Eden, Jones \& Sims (1983), the relations of causality obtained by pair comparisons are symbolised by arrows. A positive sign $(+)$, or the absence of a sign at the extremity of the arrow, indicates that the pole present in the first construct leads to the pole present in the second construct. A negative sign (-) would indicate that the pole present in the first construct would lead to the contrasting pole in the second construct. Obtaining the PEEs finishes when the decision maker starts to repeat the same concepts merely expressed in different ways.

According to Rosenhead \& Mingers (2008), on finishing the process of identifying the concepts, the decision makers can be questioned about the means necessary to reach them and or also the ends to which the concept is directed. The structure of the cognitive map is formed by the junction of the concepts, means and ends, related by links of influence.

According to Jardim (2008), the concept-ends, registered on the cognitive map, are identified by the facilitator through questions. The decision maker responds by saying that the concept in question is important so that a determined end may be reached. Next, the decision maker is questioned about the psychological opposite of the concept-end, the psychological pole. Jardim (2008) also states that the process follows this system until the decision maker replies 
that "the concept is important because it is important". In this way, the highest hierarchical level in the cognitive map is reached, the strategic objective, the greater goals. A specific concept can generate two or more concept-ends. In these cases, it is important to avoid repetition.

The framing of the map, briefly, consists of determining at which hierarchical level of the map is located each of the plans of the table of the decision making process. The higher the concept is in the hierarchy, the more it is an end and the closer it will be to being a strategic objective. On the other hand, the lower the concept is defined in the hierarchy, the more it will be a means and therefore will have the characteristic of an action.

The point of view of the decision makers reflects consequences or results of interest which are influenced by those choices and explain the values that the decision makers consider important in that context in particular (Gomes, Gomes \& Almeida, 2009).

The use of cognitive maps generates a large quantity of information on the problem, resulting in an increase in the knowledge of the decision makers in relation to the problematic situation. This characteristic of the maps can be extremely useful in the construction of the tree of points of view, as, from the map, it is possible to determine the objectives of the actors and the characteristics of the actions that the decision makers judge to be important, and, therefore, must form part of the mode of evaluating the actions.

\subsection{Construction of a Cognitive Map of a Group}

There are two types of cognitive maps, individual ones and group ones. The first approach defended by Montibeller Neto (1996), is to produce individual maps and afterwards aggregate them in groups in such a way as to allow all the members of the group to have an equal participation in the construction, given that relations of power may affect the results. In the second approach, the decision makers share the power in the organization but have conflicting interests and values as they represent different interest groups. The construction of the cognitive map of the group of decision makers is much more complex than that of an individual cognitive map. In the group, there are differences in personality, styles of interaction, power, values and concerns about the internal politics of the organization.

While through individual cognitive mapping one tries to display a person's thinking on a given problem, group or collective cognitive maps allow showing a group's thinking on the same problem. According to authors such as Rosenhead \& Mingers (2008) as well as Tergarden \& Sheetz (2003), group cognitive maps are derived either from merging individual maps or by making use of methodologies that try to avoid the creation of too large maps that could make the utilization of cognitive mapping impractical by organizations. In the case study presented in this article answers from applying questionnaires were statistically treated, leading to two different group cognitive maps as shown in section 4.1.

According to Jardim (2008), in the construction of a cognitive map of a group there are a large number of conflicting concepts but also a large number of similar concepts which can be aggregated. Although the decision makers perceive and interpret the same decision concept in a different way, in order to carry out something, they must take into account how the other decision makers perceive and interpret that context. In fact, there is an interdependence among the decision makers as regards actions.

Pesquisa Operacional, v.30, n.2, p.331-344, Maio a Agosto de 2010 
The methodology of the study was the construction of an aggregated cognitive map, with the aim of facilitating the structuring of the decision making problem. It followed the steps for the creation of a cognitive map according to the literature researched in Rosenhead \& Mingers (2008). The steps were adapted as a questionnaire was used for the construction of the cognitive maps.

\section{Case Study}

The methodological development in this research was based on Cooper \& Schindler (2003) and Günther (2003). The structure of the research was carried out based on an exploratory study, and, as research strategy, cognitive mapping was chosen due to the nature of the subject analysed. Although the maps were not validated by the employees, the methodology allows the building of cognitive maps that explains their decision making related to professional mobility.

\subsection{Collecting Data}

The data used in this research was obtained through research carried out with employees who had entered a large company in the oil sector via a civil service exam, the employees coming from diverse university degree backgrounds. All of the employees in the sample were from states in the federation other than Rio de Janeiro. This requirement was chosen because the study of professional mobility proposed was for employees from outside Rio de Janeiro who had come to the head office of this company after being contracted. It was observed that $81 \%$ of the sample was composed of men and only $19 \%$ of women. Around $64 \%$ of the employees were between 30 and 39 years old and 22\% between 40 and 49 years old. Another important piece of information concerning this sample was that $66 \%$ were married and $25 \%$ single. The remaining $9 \%$ represented employees who were separated and/or divorced.

The information was collected from the employees through a questionnaire which was prepared for this purpose. The questionnaire was sent to 619 employees (decision makers), all of whom were involved in the professional mobility decision making process. A total of 160 questionnaires were received. Three groups of decision makers were identified. As a means of enriching the work, groups 1 and 2 were combined, transforming them into a single profile, used to construct Map A (return to the state of origin or where there was an operational unit of the company studied, relinquishing the opportunities of working in the head office). As a result, group 3 was used to construct Map B (to remain at the head office of the company where, theoretically, there would be greater possibilities for professional growth in the long term). In this way, 93 employees were identified as belonging to groups 1 and 2 (return to the state of origin) and 67 employees were identified as belonging to group 3 (to remain at the head Office of the company in Rio de Janeiro/RJ).

Therefore, two cognitive maps were constructed: one representing the employees who opted for the decision to return to their state of origin, redirecting their career to an operational unit together with those who had already decided to make this decision, but who were still dependent on formal confirmation of their transfer by the company (Map A) and the other, represented by the employees who decided that the best option was to continue at the head office, prioritising the opportunities for career advancement (Map B). 


\subsection{Implementing the Method}

In this stage the following steps were used for the construction of the cognitive maps:

- Step 1: to define a label for the problem;

- Step 2: to define the primary evaluation elements (PEEs);

- Step 3: to construct concepts from the primary evaluation elements (PEEs);

- Step 4: to construct the concept hierarchy;

- Step 5: to construct the aggregate map (Group).

\section{Results}

The implementation of the method permitted the creation of two cognitive maps identified as Cognitive Map A and Cognitive Map B. The first was drawn up with the employees who share the idea of returning to the state of origin and the second drawn up with the employees who share the idea of remaining at the head office of the company. Both maps are commented on next.

\section{- Cognitive Map A}

There are various ways to read the cognitive map proposed. In accordance with the hierarchy of the concepts, it starts with concepts-means and goes to the concepts-ends. For instance, one can start the reading of the map by identifying the means in order to reach the ends proposed by the decision makers. In this case study the purpose was not to seek to explain all the existing relations, given that the map is self-explanatory at the moment when one understands the logic of the links of influence.

On the base of the Cognitive Map A (appendix 1) can be found the concept "Have lack of knowledge / maturity / experience" of the decision maker. This concept has a positive link in relation to the concept to "To believe that starting a career in the business unit". The link demonstrates that the more inexperienced and immature the decision maker is, the greater the chances that of he/she "believing" that starting a career outside the head office is the best decision to be made. Being inexperienced, he/she does not fully understand the implications of leaving the head office early. This concept also has a positive link with "Have difficulty of adaptation to life in Rio" given that the immaturity of the decision maker can lead him/her to create barriers to adapting as he/she is outside the city of origin.

The concept "Have difficulty of adaptation to life in Rio" is a key concept in the research for Map A. This is connected to practically all the other concepts, having as many positive links as negative ones. For example, the concept "Have difficulty of adaptation to life in Rio" has a positive relation with "Have health problems". In other words, the greater the difficulty in adapting, the greater the possibility of the decision maker to be experiencing health problems arising from that complication.

The concept "Have a high cost of living in Rio" has a positive link with "Have difficulty of adaptation to life in Rio", as the higher the cost of living, the greater the difficulty of adapting for the decision maker. The higher the cost of living, the lower the quality of life and, therefore, there is a negative link relation connecting "Search of better quality of life" to "Have a high cost of living in Rio". 
The concept "Have a bad social environment" is directly related to the concept "Have health problems" and this link is positive. The poor social environment increases the chances of the decision maker developing a health problem. "Have low managerial competence" positively affects the concept "To do frustrating tasks", as the lack of posture of the manager can have an influence on the choice of tasks which are not in line with the employee's function. It has a negative influence on the concept "Have the right professional profile for the business unit".

The concept "Coping with violence in Rio" has a positive link with "Have difficulty of adaptation to life in Rio". The greater the perception of violence is, the greater the difficulty in adapting to Rio de Janeiro.

In Map A, the structure of the decision making problem can be very clearly identified. That map suggests that negative aspects experienced before the transfer ended up influencing the making of the decision concerning professional mobility. At this point, it can be understood that the decision to return to the state of origin was coherent and consistent. As a matter of fact, in the environment in which the decision makers of Map A were living there were many arguments against remaining and innumerable arguments in favour of the transfer identified. The decision was consistent with the values and perceptions collected.

\section{- Cognitive Map B}

The creation of Map B respected the hierarchy of the concepts. As can be seen in Cognitive Map B (appendix 2), the concepts represent the main motivations extracted from the decision makers' responses to the research.

The profile of this group is completely different from the previous one. It is characterised by decision makers who, according to the concepts and links, managed to "Have good adaptation of family to Rio", "Have good quality of life", "Have good working environment" and, as a result of this, could naturally decide to remain in Rio de Janeiro at the company's head office. This fact was shown when observing the concepts-ends which demonstrate the search for "Rising in career", "Having perspective of increased in salary", "Having progression in career", "Having recognition and visibility" and "Having a challenging and motivating job". Lastly, the decision makers managed to "Having equilibrium / professional opportunity for spouse" and "Having family in Rio". Those were decision makers that were able to achieve an important value for them, i.e. the family, their basis to a better future.

The reading of the map began with the means in order to reach the ends proposed by the decision makers. What are the means to achieve the concept "Having good quality of life"? In Map B, it can be seen that, for the decision makers, the concept "Have access to high quality medical assistance" increases the perception of a good quality of life by the decision maker. The concepts "Have good transportation", "Have satisfaction and excitement with the job", "Have good work environment", "Have presence of the spouse", for example, have a positive relation to high quality of life. However, in spite of the fact that the decision makers define the concept "Have options of postgraduate courses of good quality" as having a positive relation to the concept "Have professional growth", that concept has both positive and negative relations to quality of life. It is positive in the sense of broadening professional horizons, but negative given that quality of life is reduced by the fact that one is relinquishing precious time with the family, with friends, for example, to dedicate to the courses mentioned. It is well known that the quality of life can be affected when doing a course of this magnitude at schools of a high level. 
Another important concept which needs to be highlighted in addition to "Have good adaptation of family to Rio" is "Have good working environment". For the decision makers, a good working environment is fundamental to reaching the higher hierarchical objectives such as "Have professional growth", "Rising in career", "Having recognition and visibility" all of which are considered to be links of positive influence. A good working environment signifies the presence of a good work team, a good manager, who gives opportunities to the group and puts the team in a position of visibility in the company. However, it was seen that the concept "Have professional growth" has a positive relation to the concept "Have a overload of work and high level of pressure". The greater the career growth is, the greater the workload and the level of pressure.

In map $B$, the structure of the decision making problem was very clearly identified, verified by the positive aspects in the permanence of the decision makers in recent years at the head office of the company in the city of Rio de Janeiro.

At this point, it was possible to see that the decision made by the group of decision makers studied to remain at the head office was coherent and consistent. That decision was strongly influenced by the positive aspects identified in the concepts "Having good quality of life", "Have good adaptation of family to Rio", "Have good transportation", "Have professional growth", "Have financial security for family", "Have perspective of increase in salary", among others identified. Obviously, the concepts "Have good adaptation of family to Rio" and "Have high quality of life" were fundamental, as they imply achievements such as "Have presence of spouse", "Have equilibrium / professional opportunities for spouse" and "Have good working environment". Without the presence of the family, all the other concepts would be affected by personal values. The decision was consistent with the values and perceptions collated. The professional mobility encountered in this group was greater.

Once family balance and a good working environment have been achieved, the objectivesends "Have perspective of increase in salary", "Have new profession challenges" and "Search for recognition and visibility" can be followed with a certain tranquillity, given that the bases (values) - the main factors in decision making - have been well established.

\subsection{Analysis of the Results}

As can be seen in cognitive Map A, the various factors which were identified as the main ones influencing the decision made to leave the head office of the company and return to the state of origin were: family $(20.62 \%)$, a search for a better quality of life $(15.64 \%)$, the personal values of each decision maker $(11.61 \%)$, the high cost of living in the city where the head office is located $(10.90 \%)$, the lack of a social environment $(9.95 \%)$, difficulty in adapting to the city where the head office is located $(8.77 \%)$, the identification of a lower quality of leadership in the management body at the head office $(4.5 \%)$ and promotion opportunities $(4.5 \%)$. As an example, consider the promotion opportunities construct: $4.5 \%$ represents the percent of respondents that have pointed out promotion of opportunities as a key factor behind their decision to move. These factors together represent $86.49 \%$ of the motivating factors which influenced the making of the decision. For the decision makers of Map A, the family was identified as the most important factor for the decision made to return to the state of origin.

It is important to highlight that, as one is dealing with a cognitive map of a group of employees, other factors were also identified as important at the moment of making the decision. For example, if the decision maker was experiencing a serious problem in terms of

Pesquisa Operacional, v.30, n.2, p.331-344, Maio a Agosto de 2010 
working environment in the department in which he/she was allocated in the head office, for this respondent the problem of working environment was a more important factor at the moment of making the decision to transfer to another unit in the company than the family itself.

The other factors are also important in the analysis of the map but it is proposed to deal with the main ones given the focus of the present study.

The decision makers of Map B represent 67 of the 160 employees who responded to the research. There was no significant difference in the information concerning the demographic profile in this group of employees used to construct map B to that mentioned in the previous chapter.

The sample is composed, in the main, of men, the civil status is predominantly married and the age band of the employees is between 30 and 39 years old.

As can be seen in cognitive Map B, the various factors which were identified as being those which most influenced the decision made to remain as the head office were: greater possibility of career development/promotion opportunities (33.86\%), good adaptation to the city where the head office is located (15.14\%), good working environment $(9.16 \%)$, prospects of an increase in salary $(7.17 \%)$, recognition/self realisation $(7.17 \%)$, family and quality of life $(6.77 \%)$ and quality of life $(4.71 \%)$. Together they represent $83.98 \%$ of the motivating factors behind the decision. Each decision maker could identify innumerable factors which influenced the making of the decision and the graphic representation attempts to explain the main ones. The other factors are also important in the analysis of the map but it is proposed, given the focus of the present study, to deal with the principal ones.

\subsection{Validation of the Method Proposed}

In this research, the process of constructing a cognitive map was followed, although, in the end, two cognitive maps A and B were constructed which clearly structured the decision making problem proposed by the author.

As a result of the maps, it was shown in Map A that the decision makers had sufficient input to make the coherent and consistent decision at that moment in their lives. It is important to remember that the map is not a statistical tool. Different facilitators leading the process of constructing the PEEs and identifying concepts may lead to a map different in scope, but, possibly, the structuring of the problem would be basically the same, given the particularities of the decision makers and their motivating factors at the moment of decision making.

In Map B, the problem structuring process was carried out with great ease. The large quantity of responses and explanations of the decision makers on each motivating factor was crucial for determining the concepts and their links of influence. The decision makers made the coherent and consistent decision as can be seen in the cognitive map drawn up, respecting the personal characteristics of each concept of the decision maker.

The application of the tool made it possible to observe the distinct profile of each group. From the responses sent, the existence of two profiles (value standards) was clearly seen in each map.

In Map A, the profile of employees fits into values that are focused in affiliation (family, children) as well as in the social context. In Map A the employees showed a lesser capacity of professional mobility. 
In Map B, on the other hand, it can be observed that the profile of the employees fits into values centred on the career, power and the need for professional growth. They are more motivated to having access to opportunities for growth and promotion, and have a greater capacity of professional mobility.

In this way, it was demonstrated that the method proposed in this work, a cognitive map, is an important decision making support tool, and that its use should be more widely disseminated in diverse knowledge areas.

\section{Conclusion}

Cognitive mapping was used in this research, in the preparation of two maps, A and B, structuring a decision making problem regarding the professional mobility of a group of employees of a large company in the petroleum sector. It was shown that, by using cognitive mapping, it is possible to effectively achieve problem structuring, thus establishing an important support tool in decision making.

Through cognitive mapping, the problem was essentially structured, which was to decide whether the employees should return to their state of origin or if they should remain at the company's head office. In the present study it was observed that decisions made by each group were strongly influenced by peculiarities of each scenario experienced and by difficulties met by each decision group when faced with opportunities of professional growth, career advancement, need for professional mobility and their personal values.

The construction of an aggregated cognitive map was carried out in an attempt to structure the decision problem. As the work progressed, a series of analyses were developed through which the application, usefulness and efficiency of the chosen method were demonstrated.

As found in the study by Hammond, Keeney \& Raiffa (2004), there are no perfect alternatives in complex decisions, however, we can conclude that the study achieved the research purpose in the sense that it demonstrated that cognitive maps can support, in many ways, the decision makers in decision making, especially in the problem structuring phase, which is the most critical phase in the whole process.

In spite of the research having been carried out after the decision was made, the results projected in maps A and B are coherent and consistent with the decisions made and raise new questions regarding the theme, which is, in essence, the aim of any scientific study. The profiles of employees represented by Map A and by Map B were not identified a priori. These profiles have indeed been deduced from each of the two maps. What was the object of one a priori classification were groups 1, 2 and 3 of employees. That classification was the basis for the construction of these two maps.

It can be deduced that through the construction of the maps, two groups of employees with different profiles exist in the decision making criteria. In map A we can identify the group of employees with characteristics of very strong affiliation and which, consequently, demonstrated less capacity of adaptation and professional mobility. The need for affiliation, distance from family and social context strongly influenced the decision made to return to a company unit in their state or nearer to their state of origin.

In Map B we can identify the group of employees more motivated by the possibility of career growth, promotion opportunities, good prospects of an increase in salary and with a 
need for recognition and self-realisation. It can be deduced that the employees from this group possess, as a characteristic, a larger capacity of adaptation, need for power and professional growth, besides presenting greater professional mobility than the other group.

\section{Acknowledgements}

The authors are grateful to the referees for their insightful comments on the first version of this paper. This work was partially supported by CNPq through Research Projects No. 310603/2009-9 and 502711/2009-4.

\section{References}

(1) Bana e Costa, C.A.; Beinat, E. \& Vickerman, R. (2001). Model-structuring and impact assessment: qualitative analysis of policy attractiveness. CEG-IST Working Paper n.25.

(2) Bastos, A.V.B. (2002). Cognitive Maps e a Pesquisa Organizacional: Explorando Aspectos Metodológicos. Estudos de Psicologia, 7, Special Issue, 65-77.

(3) Chaplin, J.P. (1985). Dictionary of Psychology. Random House, New York.

(4) Clemen, R.T. \& Reilly, T. (2001). Making Hard Decisions with Decision Tools ${ }^{\circledR}$. Duxbury / Thomson Learning, Pacific Grove.

(5) Cooper, D.R. \& Schindler, P.S. (2003). Métodos de Pesquisa em Administração. Bookman, Porto Alegre.

(6) Eden, C. (1988). Cognitive Mapping. European Journal of Operational Research, 36, $1-13$.

(7) Eden, C.; Jones, S. \& Sims, D. (1983). Messing about problems. Pergamon, Oxford.

(8) Fiol, C.M. \& Huff, A.S. (1992). Maps for Managers: Were Are We? Where do We Go from Here? Journal of Management Studies, 29(3), 267-286.

(9) Gomes, L.F.A.M.; Gomes, C.F.S. \& Almeida, A.T. (2009). Tomada de Decisão Gerencial: Enfoque Multicritério. $3^{\mathrm{a}}$ ed. Atlas, São Paulo.

(10) Günther, H. (2003). Como Elaborar um Questionário (Série: Planejamento de Pesquisa nas Ciências Sociais, No 01). UNB, Laboratório de Psicologia Ambiental, Brasília, DF. URL: <www.psi-ambiental.net/pdf/01Questionario.pdf>.

(11) Hammond, J.S.; Keeney, R.L. \& Raiffa, H. (2004). Decisões Inteligentes. $3^{\mathrm{a}}$ ed. Campus, Rio de Janeiro.

(12) Jardim, S.B. (2008). Cognitive maps: Um caminho para construir estratégias. Available in <http://www.pucrs.br/feng/dec/civil/professores/jardim/artigos-mapascognitivos.pdf $>$. Captured in 27/08/2008.

(13) Keeney, R.L. \& Raiffa, H. (1999). Decisions with multiple objectives: preferences and value tradeoffs. Cambridge University Press, Cambridge.

(14) Keeney, R.L. (1992). Value-Focused Thinking: A Path to Creative Decision Making. Harvard University Press, Cambridge. 
(15) Montibeller Neto, G. (1996). Cognitive maps: Uma Ferramenta de Apoio à Estruturação de Problemas. Florianópolis. Dissertação de Mestrado em Engenharia de Produção Programa de Pós-Graduação em Engenharia de Produção, Universidade Federal de Santa Catarina. UFSC, Florianópolis.

(16) Rosenhead, J. \& Mingers, J. (2008). Rational Analysis for a Problematic World Revised. John Wiley \& Sons, Chichester.

(17) Tegarden, D.P. \& Sheetz, S.D. (2003). Group cognitive mapping: a methodology and system for capturing and evaluating managerial and organizational cognition. Omega, 31(2), April, 113-125.

\section{Appendix 1 - Map A}

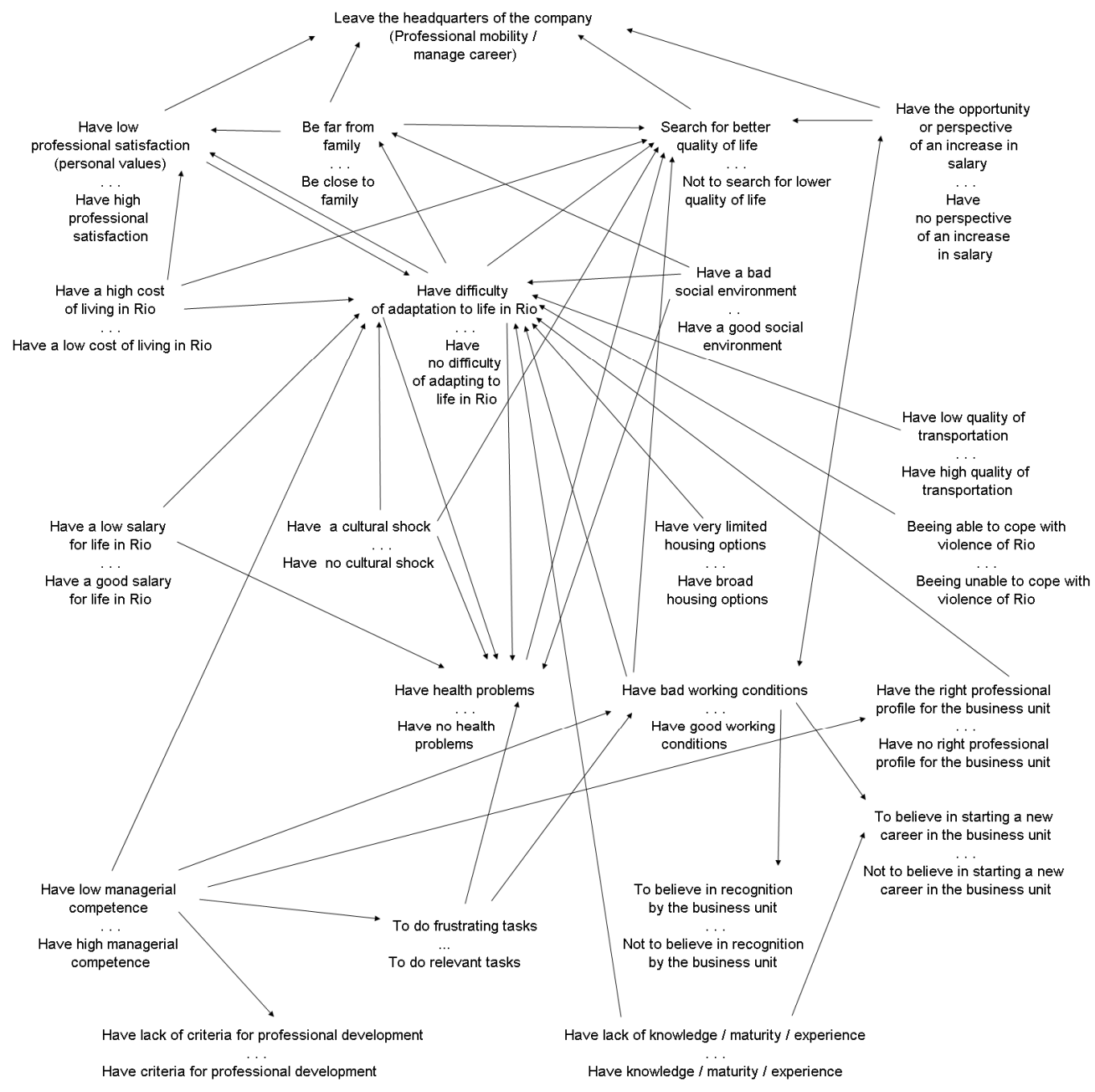

Note: $\quad \ldots=$ instead of. 


\section{Appendix 2 - Map B}

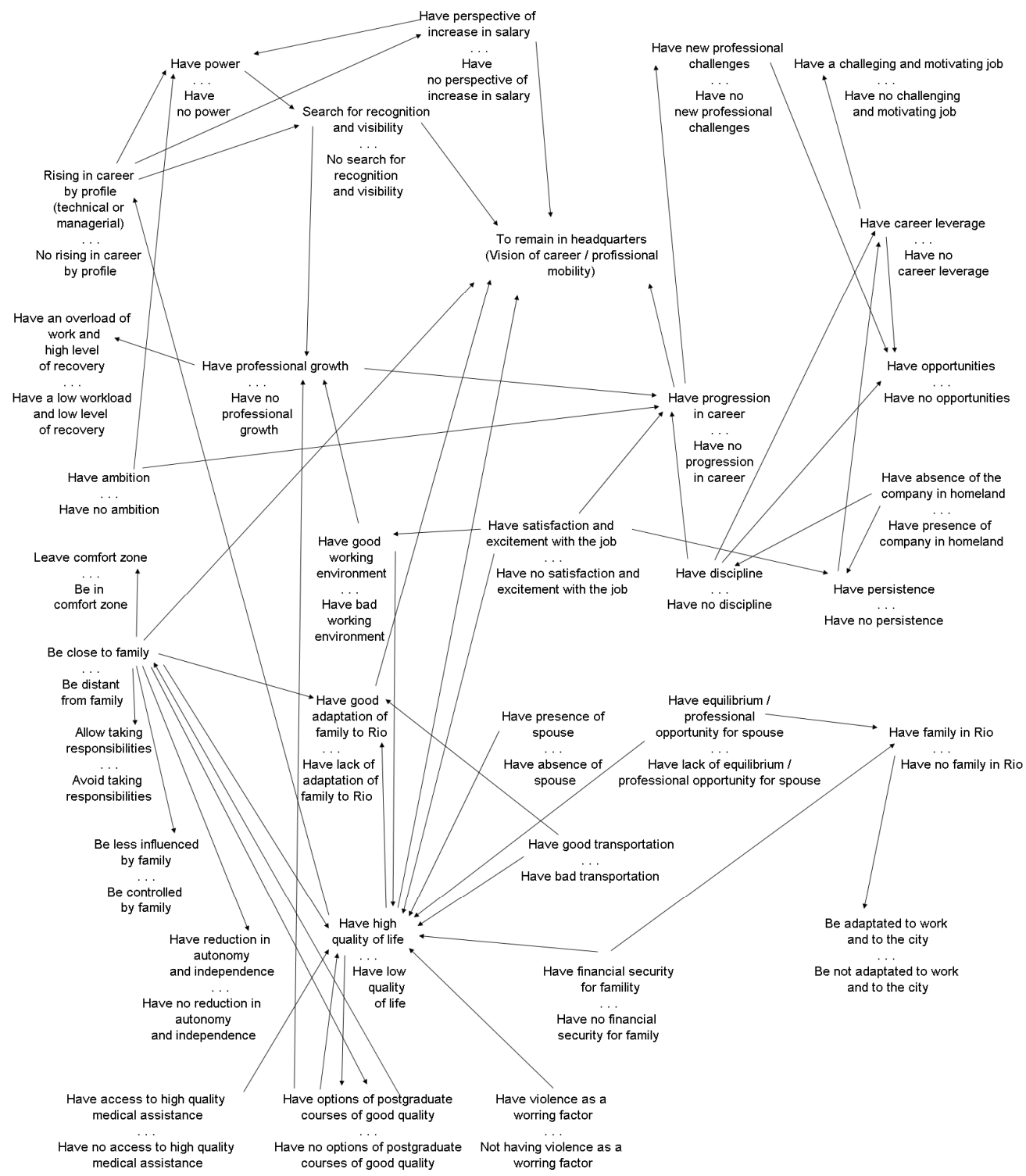

Note: $\quad \ldots=$ instead of. 